\title{
PERAN MATA KULIAH KERJA PRAKTEK PADA TUGAS AKHIR MAHASISWA PROGRAM STUDI TEKNIK ARSITEKTUR DI JAKARTA
}

\section{The Role of Practical Work Courses In The Final Project of Architecture Engineering Study Programs in Jakarta}

\author{
Kiki Maria ${ }^{1 *}$ \\ 1 Jurusan Teknik Arsitektur Universitas Bung Karno, Jl. Kimia No.20, RT.10/RW.1, Pegangsaan, Kec. \\ Menteng, Kota Jakarta Pusat, Daerah Khusus Ibukota Jakarta 10320, Indonesia
}

\section{Informasi artikel \\ Diterima: 19/12/2019 \\ Direvisi : 29/12/2020 Disetujui: $23 / 01 / 2020$}

\begin{abstract}
Abstrak
Kerja praktek merupakan salah satu syarat untuk mengambil tugas akhir (skripsi) pada Program Studi Teknik Arsitektur. Kerja Praktek Dilaksanakan oleh mahasiswa jurusan Arsitektur selama kurang lebih empat (4) bulan untuk melakukan aktivitas pada proyek konstruksi tertentu yang ada kaitannya dengan bidang arsitektur misalnya perencanaan, pelaksanaan dan pengawasan pada institusi diluar kampus dalam hal ini Kontraktor atau Konsultan Perencana. Penelitian ini untuk mengetahui apakah mahasiswa didalam melaksanakan Tugas Akhir juga menerapkan pengalaman yang diperoleh selama melaksanakan Kerja Praktek. Berdasarkan latar belakang di atas, maka kami tim pengusul sangat tertarik dan ingin mencoba melakukan penelitian dengan judul "Peran Mata Kuliah Kerja Praktek Pada Tugas Akhir Mahasiswa Program Studi Teknik". Penelitian ini dilakukan dengan beberapa tahapan, yaitu tahapan survei, tahapan pengolahan data, dan tahapan penarikan kesimpulan. Dalam tahapan survei dilakukan pengambilan data- data primer dengan melakukan komparasi antara Laporan Kerja Praktek dan Laporan Tugas Akhir. Komparasi dilakukan pada beberapa perguruan tinggi yang menurut rencana akan dipilih sebagai lokasi pengambilan sampling yaitu: Universitas Bung Karno, Universitas Pancasila, Universitas Kristen Indonesia dan Universitas "YAl". Tahapan kedua, dilakukan pengolahan data dengan menggunakan metode penaikan sampel, metode analisis, dan pengujian hipotesis. Tahapan terakhir dilakukan penarikan kesimpulan tentang Peran Mata Kuliah Kerja Praktek Pada Tugas Akhir Mahasiswa Program Studi Teknik Arsitektur.
\end{abstract}

Kata Kunci: kerja praktek, tugas akhir, mahasiswa teknik, arsitektur

\begin{abstract}
Practical work is one of the requirements for taking the final project (thesis) in the Architectural Engineering Study Program. Practical Work Performed by students majoring in Architecture for approximately four (4) months to carry out activities on certain construction projects that are related to the field of architecture such as planning, implementation and supervision of institutions outside the campus in this case the Contractor or Planning Consultant. This research is to find out whether students in carrying out the Final Project also apply the experience gained while carrying out practical work. Based on the above background, we are very interested in proposing and trying to do research with the title "The Role of Practical Work Subjects in Engineering Student Program Final Project". This research was conducted in several stages, namely the survey stage, the data processing stage, and the conclusion drawing stage. In the survey stage, primary data collection is carried out by making a comparison between the Job Training Report and the Final Task Report. Comparisons were made at several universities which according to the plan would be chosen as sampling locations, namely: Bung Karno University, Pancasila University, Indonesian Christian University and "YAl" University. The second stage, data processing is done using the method of raising the sample, the method of analysis, and testing the hypothesis. The last stage was drawing conclusions about the Role of Practical Work Subjects in the Final Project of the Architectural Engineering Study Program.
\end{abstract}

Keywords: practical work, final project, engineering students, architecture.

*Penulis Korespondensi. Tel: 0213192 2441; Handphone: 081290003924

email : kikimaria@ubk.ac.id; kimarch99@gmail.com 


\section{PENDAHULUAN}

Kerja praktik (KP) adalah salah satu mata kuliah wajib yang dilaksanakan pada tiap semester 6. Kerja praktik juga merupakan salah satu syarat untuk mengambil tugas akhir (skripsi). Dilaksanakan oleh mahasiswa jurusan Arsitektur selama kurang lebih empat (4) bulan untuk melakukan aktivitas pada proyek konstruksi tertentu yang ada kaitannya dengan bidang arsitektur misalnya perencanaan, pelaksanaan dan pengawasan pada institusi diluar kampus dalam hal ini Kontraktor atau Konsultan Perencana. Pada akhir program studi selama semester berjalan mahasiswa diwajibkan untuk menyusun laporan hasil pelaksanaan, melaksanakan, dan melaksanakan ujian pada akhir semester. Rangkaian kegiatan tersebut dilaksanakan dalam jangka waktu satu semester. Satu bulan didefinisikan sebagai 30 hari kerja. Jumlah jam kerja dalam satu hari kerja disesuaikan dengan jenis aktivitas kerja praktik dan situasi di institusi tempat kerja praktik. Jenis aktivitas yang dilakukan selama pelaksanaan kerja praktik di tempat kerja praktik meliputi aktivitas yang ditawarkan oleh institusi tempat pelaksanaan KP atau aktivitas yang diusulkan mahasiswa kepada institusi tempat pelaksanaan KP beberapa perguruan tinggi yang mempunyai program studi teknik Arsitektur diantaranya adalah Universitas Bung Karno (UBK), Universitas Pancasila (UP), Universitas Kristen Indonesia dan Universitas YAI.

Dengan mengikuti Kerja Praktek diharapkan mahasiswa dapat melihat dan memahami penerapan \& perkembangan ilmu serta teknologi dalam bidang teknik secara langsung dan nyata di dunia kerja.

Tujuan penelitan ini untuk mengetahui apakah mahasiswa didalam melaksanakan Tugas Akhir juga menerapkan pengalaman yang diperoleh selama melaksanakan Kerja Praktek

Penelitian tentang peranan kerja Praktek pada Tugas akhir mahasiswa program studi teknik ada beberapa yang berhubungan. Namun, penelitian-penelitian tersebut sebagian besar dilakukan pada mahasiswa lebih mengenai Kerja Praktek yang dilakukan. Oleh karena itu, penelitian ini lebih menekankan pada peran kerja praktek hubungannya dengan Tugas Akhir.

\section{METODOLOGI}

Metodologi penelitian adalah gambaran, panduan yang berisi langkah-langkah untuk mencapai tujuan dari penelitian. Metodologi membantu penelitian agar lebih terarah, teratur dan sistematis dengan mengikuti langkah dari awal sampai mendapatkan hasil yang ingin dicapai. Adapun langkah-langkah penelitian pada tulisan ini adalah sebagai berikut:

a. Identifikasi masalah dan merumuskan masalah.

Tahap awal penelitian adalah mengumpulkan Data Laporan Kerja Praktek, Skripsi dan Tugas Akhir Mahasiswa Univesitas Bung Karno dan Perguruan Tinggi yang terkait. Jika dimungkinkan mengunjungi institusi tempat dimana mahasiswa melaksanakan Kerja Praktek.

Tujuan dari kunjungan ini untuk mengetahui metode pembelajaran institusi di dalam membimbing mahasiswa Kerja Praktek.

b. Merancang alur penelitian dan memilih metode.

Metode yang tepat untuk dipakai di dalam penelitan ini adalah komparasi dari empat (4) Universitas program studi Teknik Arsitektur diantaranya adalah Universitas Bung Karno (UBK), Universitas Pancasila (UP), Universitas Kristen Indonesia dan Universitas YAI berdasarkan variable Independen, yaitu: Bidang pekerjaan dan Variabel Dependen: Mahasiswa-Alumni-UsiaKerja praktek-Tugas Akhir.

\section{HASIL DAN PEMBAHASAN}

\section{Tahap Identifikasi}

Pada tahap ini, dilakukan penyebaran angket kepada responden yang berada di 4 universitas yang menjadi subjek penelitian dengan mahasiswa Tugas Akhisr sebagai objeknya. Tabel 1, memperlihatkan hasil angket dari responden yang menjadi objek penelitian. Dari tabel tersebut didapatkan data para responden yang menjadi acuan analisis dari penelitian ini. 
Tabel 1 Data responden

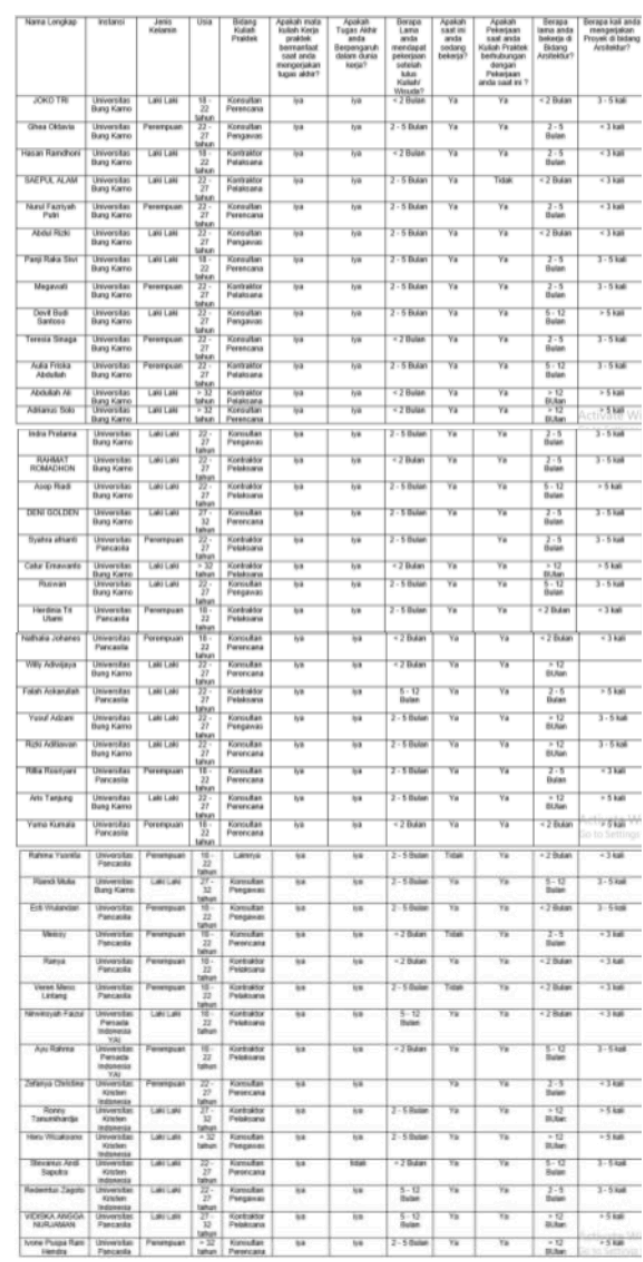

Tahap Analisis

Tahapan analisis dilakukan dengan mempelajari laporan kerja praktek, skripsi dan tugas akhir. Permasalahan yang dihadapi adalah kecil atau bahkan tidak mungkin dilakukan dengan cara wawancara atau kuesioner karena pada umumnya setelah menyelesaikan Tugas Akhir dan dinyatakan lulus mahasiswa akan meninggalkan kampus untuk memasuki dunia kerja. Berikut ditampilkan pada Gambar 1-12 persentase jawaban dari 106 orang responden terhadap pertanyaan kuesioner yang diberikan.

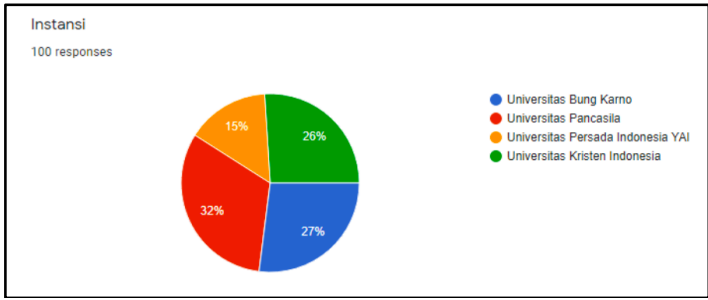

Gambar 1 Data responden dari 4 instansi

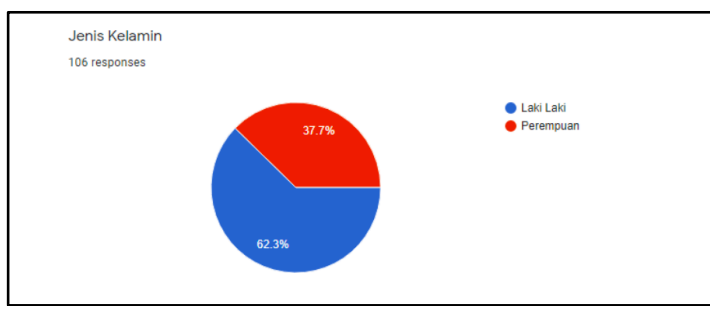

Gambar 2 Data jenis kelamin responden

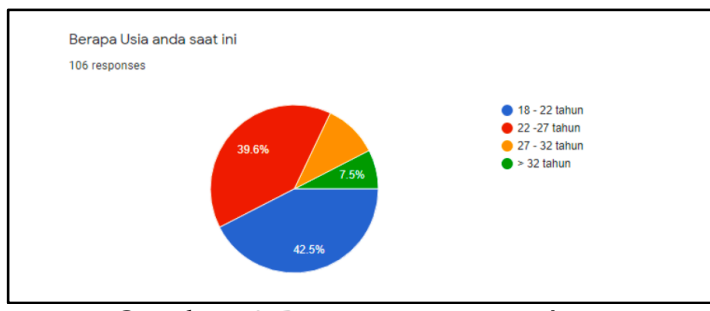

Gambar 3 Data usia responden

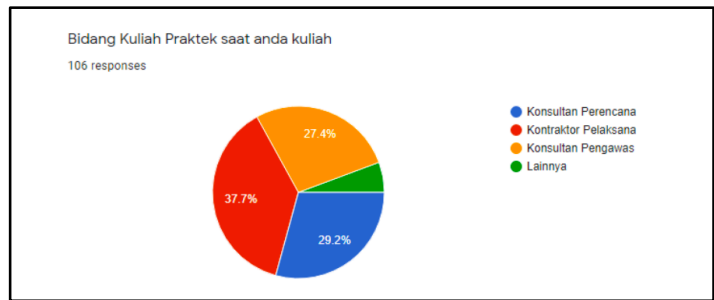

Gambar 4 Data bidang kuliah responden

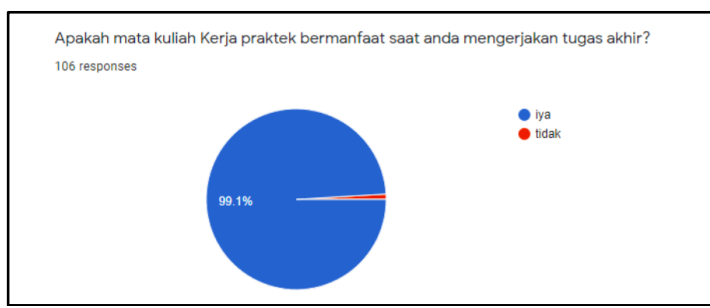

Gambar 5 Data manfaat mata kuliah kerja praktek

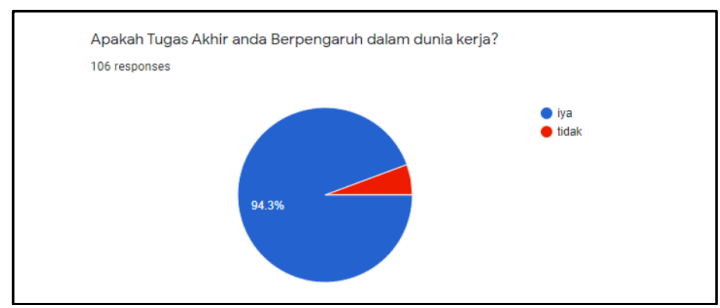

Gambar 6 Data pengaruh tugas akhir terhadap dunia kerja

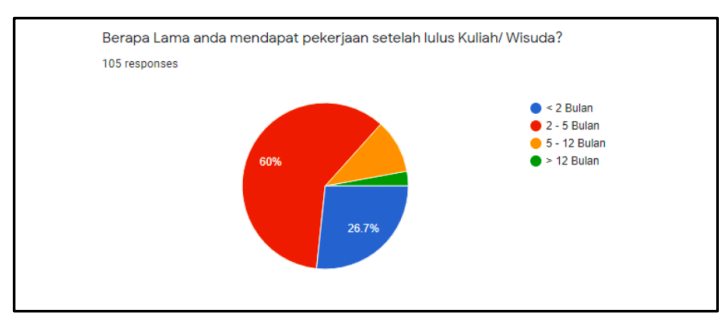

Gambar 7 Data waktu tunggu lulusan mendapatkan pekerjaan 


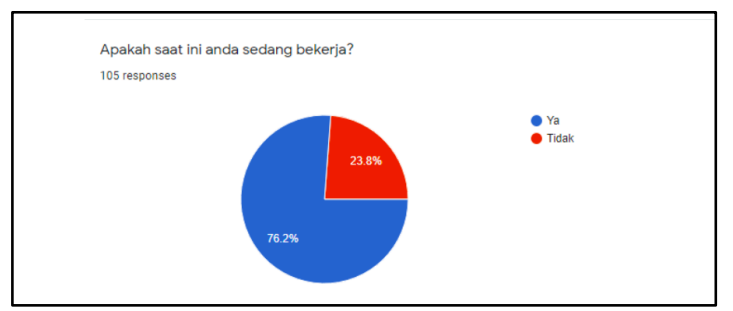

Gambar 8 Data lulusan yang sudah bekerja

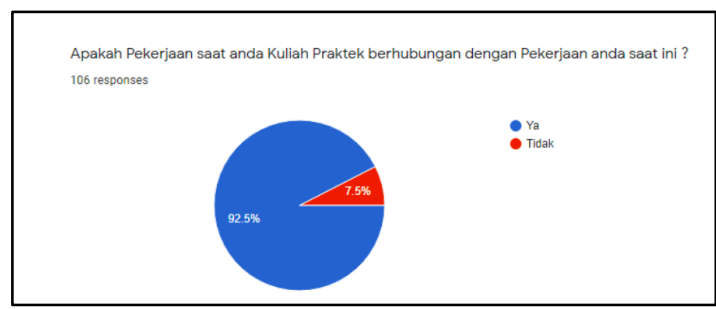

Gambar 9 Data hubungan pekerjaan dengan kuliah kerja praktek

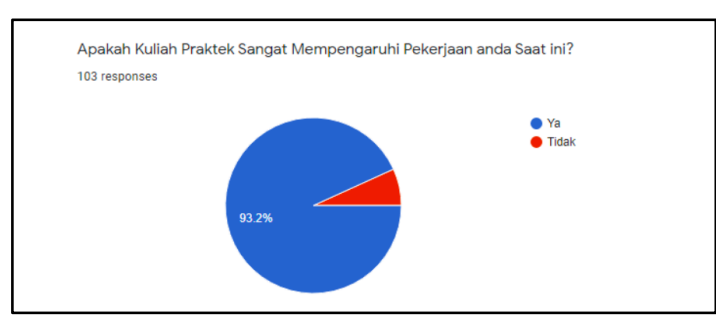

Gambar 10 Data pengaruh pekerjaan dengan kuliah kerja praktek

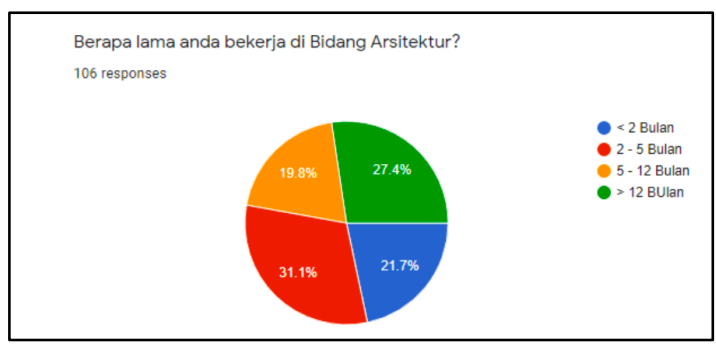

Gambar 11 Data lama pekerjaan di bidang arsitektur

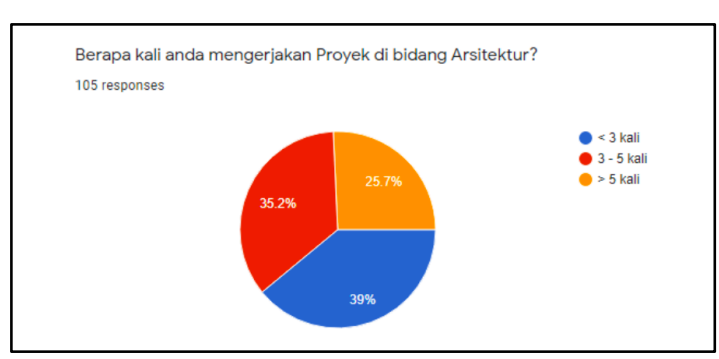

Gambar 12 Data jumlah proyek terkait bidang arsitektur

Dari hasil angket kuisioner dengan online Google form yang disebarkan ke mahasiswa dan alumni berikut Hasil perbandingan Persentase Pekerjaan setelah lulus kuliah dari jurusan Teknik Arsitektur dari 4 Universitas di Jakarta.

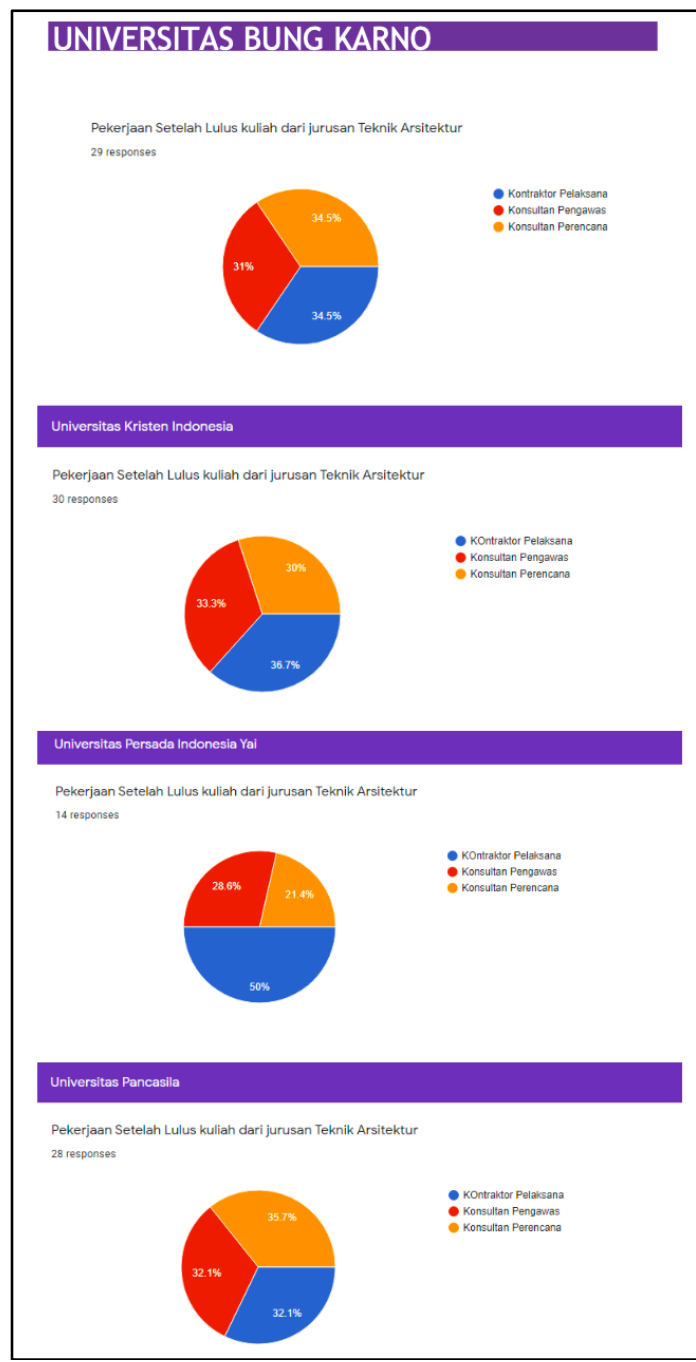

Gambar 13 Data hasil perbandingan pekerjaan setelah lulus kuliah di tiap universitas di Jakarta

Dari hasil angket kuisioner yang disebarkan ke mahasiswa dan alumni jumlah persentase alumni yang bekerja berkaitan dengan Teknik Arsitektur dari empat (4) Universitas program studi teknik Arsitektur diantaranya adalah Universitas Bung Karno (UBK), Universitas Pancasila (UP), Universitas Kristen Indonesia dan Universitas "YAl" yaitu alumni yang bekerja dibidang Konsultan Peencana adalah $35,7 \%$, alumni yang bekerja dibidang Konsultan Pengawas adalah 32,1\% dan alumni yang bekerja dibidang Kontraktor Pelaksana 32,1\%, sehingga jumlahnya hampir sama merata di tiga (3) bidang tersebut. 


\section{SIMPULAN}

Dilihat dari prosentase terbesar adalah alumni yang bekerja dibidang Konsultan perencana, Alumni yang bekerja berkaitan dengan Teknik Arsitektur adalah di konsultan Perencana karena ada keterkaitan dengan Tugas Akhir adalah perencanaan dan perancangan.

Jadi, peran mata kuliah Kerja Praktek pada Tugas Akhir mahasiswa manfaatnya untuk ke dunia kerja baik itu pengalaman bekerja praktek dan kemampuan perencanaan perancangan pada tugas akhir yang bisa diterapkan dalam dunia kerja.

\section{DAFTAR PUSTAKA}

Undang-undang Nomor 28 Tahun 2002 Tentang Bangunan Gedung .

Undang-undang Nomor 06 Tahun 2017 Tentang Arsitek.

Peraturan Pemerintah Nomor 36 Tahun 2005 Tentang Undang-undang no 28 Tentang Bangunan Gedung.

Prasetyo, Iftadi, \& Rochman, (2010). Perancangan Sistem Tugas Akhir dan Kerja Praktek di Jurusan Teknik Industri UNS. PERFORMA Vol. 9, No. 1 Maret 2010. 